\title{
Effects of wild fishes on waste exportation from a Mediterranean fish farm
}

\author{
Rubén Vita ${ }^{1, *}$, Arnaldo Marín ${ }^{1}$, Juan Antonio Madrid ${ }^{2}$, Blanca Jiménez-Brinquis' ${ }^{1}$, \\ Augusto Cesar ${ }^{1}$, Lázaro Marín-Guirao ${ }^{1}$
}

${ }^{1}$ Departamento de Ecología e Hidrología, and ${ }^{2}$ Departamento de Fisiología, Facultad de Biología, Universidad de Murcia, 3100 Murcia, Spain

\begin{abstract}
This study investigated the role of wild fishes associated with marine farms as potential consumers of organic waste in the water column and sediment. Experiments were carried out at a fish farm in a semi-enclosed bay in the Mediterranean Sea (SE Spain). Sediment traps collected organic waste from net-pens in the water column at different depths during June and July 2001 and benthic caging experiments were carried out on the sediment from October 2000 to January 2001. The experiment showed that about $80 \%$ of the particulate organic matter leaving the rearing net-pens may be consumed before it settles on the sediment. Significant changes in the nutrient quality of the organic matter exported are also due to consumption by wild fishes. Wild fishes thus play an important role in recycling the organic matter of the sediment, and regulate the benthic community structure. Our results indicate that the trophic role of wild fishes should be considered when evaluating the environmental impact of fish farms.
\end{abstract}

KEY WORDS: Aquaculture $\cdot$ Wild fishes $\cdot$ Fish farm $\cdot$ Sea-cage $\cdot$ Organic waste $\cdot$ Mediterranean Sea

\section{INTRODUCTION}

Intensive finfish aquaculture, as commonly practised in net-pens in the Mediterranean Sea, involves the supply of high-quality artificial feeds. This generates large amounts of organic wastes, which are directly released into the receiving environment. A range of environmental effects has been related to net-pen aquaculture, particularly in regard to energy and nutrient fluxes, pelagic and benthic biomass and community structure, fish stocks, sedimentation rates, oxygen depletion and shifts in the algal community. Many of these are directly related to nutrient pollution, and several studies have shown that 70 to $80 \%$ of nutrients added in aquaculture are lost to the environment in the form of metabolic waste, faeces and uneaten food fragments (Kaushik 1998, Lemarié et al. 1998, Lupatsch \& Kissil 1998). The deposition of particulate matter from aquaculture net-pens has been identified as the main cause of negative environmental impacts (Gowen et al. 1991, Pillay 1992, Read \& Fernandes 2003). The quan- tity and quality of the feed are the most important factors determining nutrient loss to the environment, since these factors determine both feed wastage and excretion loss (Persson 1990, Cho \& Bureau 1997). However, not only the chemical composition of the feed influences the rate at which it is lost to the environment, and feeding methods may be as important as any other factor (Levings 1994).

Wild fishes tend to concentrate around fish farms (Dempster et al. 2002) and the consumption of farm emissions cannot be explained only by the accidental consumption by wild fish of sedimented faeces with sediment material alone (Johansson et al. 1998). High deposit rates may cause an accumulation of organic detritus in the sediment if removal by physical, chemical and biological means cannot assimilate such an input. Usually the accumulation of organic output is confined to the area directly beneath the net-pens and its immediate surroundings (Henderson et al. 1997, McGhie et al. 2000). Such high waste inputs can produce strong changes in the structure of benthic com- 
munities (Mazzola et al. 1999, Karakassis et al. 2000, Mirto et al. 2002) and may even result in the formation of bacterial mats and anoxic conditions. Benthic fauna also affect the mineralisation of organic matter, stimulating total benthic metabolism (Heilskov \& Holmer 2001). In short, future developments in finfish aquaculture need to better address the main question of holding capacity for released waste in relation to the entire ecosystem.

This study aimed to elucidate the role of wild fishes associated with marine farms as potential organic waste-consumers in the water column as well as in the sediment. Our objectives were: (1) to evaluate the consumption of organic farm waste by wild fishes in the water column; (2) to identify changes in sediment characteristics (organic matter, $\mathrm{C}: \mathrm{N}$ atomic ratio, ammonium, sulphide) due to activities of wild fishes; (3) to describe the effects that ichthyofauna have on the composition and structure of benthic macrofauna.

\section{MATERIALS AND METHODS}

The study was carried out in Hornillo Bay, Murcia, SE Spain, where floating cultivation net-pens have been used for the commercial cultivation of gilt-head sea bream Sparus aurata and European sea bass Dicentrarchus labrax for more than a decade. The position of the fish farm is $37^{\circ} 24^{\prime} 36.2^{\prime \prime} \mathrm{N}, 1^{\circ} 33^{\prime} 30.1^{\prime \prime} \mathrm{W}$. The standing biomass of commercial fishes in the farm was $120000 \mathrm{~kg}$ during the experimental period. The water column was well oxygenated throughout the study period, and no deoxygenation episodes were registered. Salinity ranged from 37 to $38 \mathrm{mg} \mathrm{l}^{-1}$, and water temperature ranged from $15^{\circ} \mathrm{C}$ in winter to $25^{\circ} \mathrm{C}$ in summer.

Counts of wild fishes in the water column were conducted at a depth of $5 \mathrm{~m}$ by 2 divers in the water surrounding the cages in October 2000, January and June 2001. The visual counts aimed at estimating the relative abundance of the dominant species. Counts were performed under conditions of good visibility, i.e. visibility $>15 \mathrm{~m}$. Each count covered an area of approximately $5 \mathrm{~m}$ wide, $5 \mathrm{~m}$ long and $10 \mathrm{~m}$ deep; 5 rapid visual counts lasting $5 \mathrm{~min}$ each were conducted at 4 different stations around the net-pen area on 3 different days each month. Counts of wild benthic fishes were performed following the same methodology, but visual counts covered a benthic area of approximately $5 \mathrm{~m}$ wide and $5 \mathrm{~m}$ long.

Benthic caging experiments. The experimental period ran from 18 October 2000 to 23 January 2001, and the experiments were carried out over fine-sand sediments at a depth of $10 \mathrm{~m}$. The sediment of the area showed a strongly negative redox potential in the first
$3 \mathrm{~cm}(-111$ to $-206 \mathrm{mV})$ during the experimental period. The sediment was sampled at the beginning and at the end of the experimental period. We randomly selected 4 experimental stations under the rearing net-pens containing commercial fishes. At each of these stations, 3 different treatments were carried out simultaneously:

Exclusion cages: These were plastic-mesh cages with a large mesh size $(20 \mathrm{~mm})$, designed to prevent access of wild fishes. This mesh size allowed the circulation of water, and minimised trapping of organic matter, while allowing free movement of the mesofauna. The cages had a square base of $45 \mathrm{~cm}$ wide, $32 \mathrm{~cm}$ long and a height of $22 \mathrm{~cm}$.

Open cages: These cages retained the side walls of the above cages, but the top part was removed to allow access to the ichthyofauna of the area.

Control: Controls used no artificial structure in order to evaluate the effect that the mesh of the experimental cages had on the benthic environment of the immediate area.

Water column assays. The experiments were carried out in 2 net-pens ( $5 \mathrm{~m}$ long, $5 \mathrm{~m}$ wide and $5 \mathrm{~m}$ deep) in $10 \mathrm{~m}$ of water from 25 June to 23 July 2001. Samples affected by resuspension caused by storms were discarded. European sea bass Dicentrarchus labrax were obtained from the fish farm and randomly distributed in the net-pens, so that they contained 22000 fish, each of $100 \mathrm{~g}$ body weight, stocked at densities of approximately $15 \mathrm{~kg} \mathrm{~m}^{-3}$. Fish were maintained under selffeeding conditions. They were fed commercial extruded pellets (ProAqua, standard $3 \mathrm{~mm}$ ) using 'ondemand' feeders (Sterner, Sweden).

The flux of particulate matter under the net-pens was measured using cylindrical sediment traps (100 cm height and $16 \mathrm{~cm}$ diameter). At the base of the funnel, a cone forced the particles into a $250 \mathrm{ml}$ replaceable polyethylene container. After putting the container in place, the base of the funnel was sealed with a plug thread. Some funnels were directly clamped to the bottom of the net-pen and some were clamped to taut wires running between an anchor weight and a subsurface buoy $4 \mathrm{~m}$ below the net-pen (Fig. 1). Divers deployed 4 randomly located traps under each net-pen. To avoid the contagious effects of organic wastes, the sediment traps were randomly relocated on a weekly basis. To check for the presence of ambient particles, a further 3 control traps were placed $100 \mathrm{~m}$ from the fish farm. The location of traps relative to a net-pen may significantly affect the rates of waste trapped because of hydrodynamic transport phenomena. However, such a problem did not arise in this experiment since all traps were randomly distributed directly under the net-pen area in such way that the only difference between trap locations was in 
depth, which was always less than $4 \mathrm{~m}$. Traps were left in the water for 24 to $48 \mathrm{~h}$ before being retrieved for analysis.

Chemical analyses. Sediment samples were taken by divers using cylindrical hand-operated corers. The top $3 \mathrm{~cm}$ of the sediment were used for chemical analysis. The samples were immediately transported in containers to the laboratory and refrigerated at $4^{\circ} \mathrm{C}$. The sediment was dried in an oven at $60^{\circ} \mathrm{C}$ to a constant weight. Organic matter was determined as the loss on ignition after $5 \mathrm{~h}$ at $450^{\circ} \mathrm{C}$ in a furnace. Sediment grain size was assessed by dry-sieving with a mechanical shaker through a series of sieves $(2,1,0.5$, 0.25 and $0.064 \mathrm{~mm}$ mesh), in accordance with the Wentworth scale (Buchanan 1984), to determine the content of gravel, sand and lime. Carbon (C) and nitrogen $(\mathrm{N})$ content of those sediment particles that passed through a $0.064 \mathrm{~mm}$ mesh, were determined using a Carlo Erba Inst. EA 1108 Elemental Analyser. Particulate organic carbon (POC) content was determined by addition of $\mathrm{HCl}(1: 1)$ followed by heating at $80^{\circ} \mathrm{C}$ to remove the inorganic carbon component. The atomic organic ratio C:N (\%) was calculated using a C:N elemental analyser. Interstitial water sediment was extracted by centrifuging the samples to $1650 \times g$ at $4^{\circ} \mathrm{C}$ for $10 \mathrm{~min}$, and their total ammonia nitrogen (TAN) content was then analysed by means of an ammonium

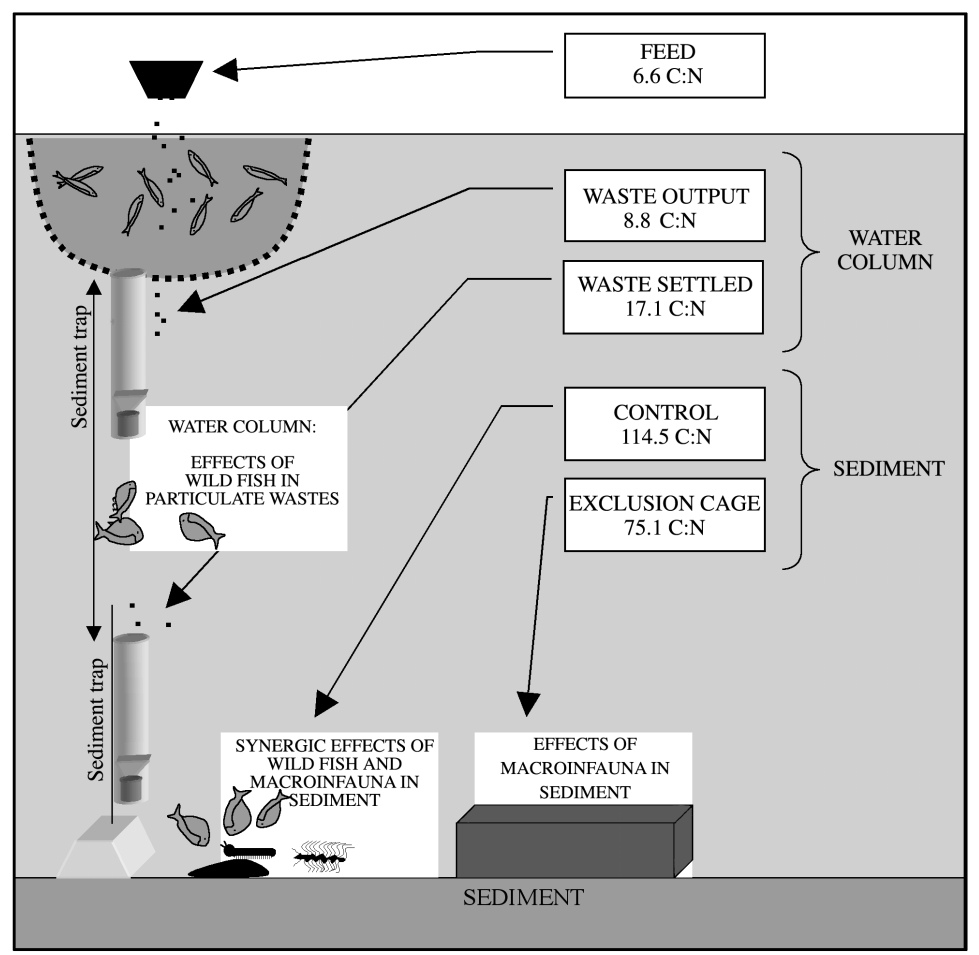

Fig. 1. Effects of wild fishes on nutritional value of organic wastes during experiments. Nutritional quality is expressed as changes in $\mathrm{C}: \mathrm{N}$ atomic ratio
Orion selective electrode according to the protocols described in APHA (1995). Acid-volatile sulphides (AVS) were determined following the procedure described by Allen et al. (1993). Briefly, approximately $5 \mathrm{~g}$ of wet sediment was placed in a flask with $100 \mathrm{ml}$ deionised water and stirred with a magnetic rod (all parts of the apparatus had previously been deoxygenated with bubbling nitrogen). The samples were purged for $10 \mathrm{~min}$ with nitrogen at a flow rate of $40 \mathrm{~cm}^{3}$ $\mathrm{min}^{-1}, 20 \mathrm{ml} \mathrm{HCl}(6 \mathrm{M})$ was injected, and the sample allowed to react for 30 min under bubbling nitrogen at $20 \mathrm{~cm}^{3} \mathrm{~min}^{-1}$ and stirring with a magnetic rod. Sulphide was trapped in impingers filled with $80 \mathrm{ml} \mathrm{NaOH}$ $(0.5 \mathrm{M})$. The sulphide trapped in the $\mathrm{NaOH}$ solution was measured with an ion-selective silver/sulphide electrode (ThermoOrion, Model 9616).

The samples from the sediment traps were centrifuged at $4^{\circ} \mathrm{C}$ for $10 \mathrm{~min}$ at $1650 \times \mathrm{g}$. The overlying water was then removed carefully with a Pasteur pipette, and settled particles were dried in an oven at $60^{\circ} \mathrm{C}$ to a constant weight. Organic matter was determined as loss on ignition after $5 \mathrm{~h}$ in a furnace at $450^{\circ} \mathrm{C}$. Carbon and nitrogen were determined for the dry, ground, settled particles using an elemental analyser, as described above for the sediment.

Benthic infaunal analyses. For biological analyses, sediment (including the overlying water) was sampled by divers using a hand-operated grabber $\left(625 \mathrm{~cm}^{2}\right.$ area) at the end of the experimental period. Samples were then sieved through $1.0 \mathrm{~mm}$ screens to separate the macrofauna. The samples were fixed with $4 \%$ buffered formalin in seawater on the day of collection. Infauna were separated, identified to the lowest practicable level and quantified.

Statistical analyses. Univariate and multivariate procedures were applied to analyse biotic and abiotic data. The univariate procedure, analyses of variance (ANOVA), was applied whenever data or transformations fulfilled ANOVA assumptions (KolmogorovSmirnov normality test and Bartlett's homoscedasticity test). When a non-parametric analysis was needed, Kruskal-Wallis's test was applied. These univariate procedures were applied (computer application Statistica v4.5) to data obtained from the sediment traps, to the sediment's environmental data and to the community indices. The ShannonWiener diversity index was calculated as $H=$ $-\sum p_{i} \log _{2}\left(p_{i}\right)$, Margalef's richness index as $(S-1) / \operatorname{Ln}(N)$, Pielou's evenness index as $H_{\text {max }}$ $\log _{2}(S)^{-1}$ and Simpson's dominance index as $\sum p_{i}{ }^{2}$; where $S=$ number of species, $\mathrm{N}=$ number of individuals, $p_{i}=$ proportion of total 
sample belonging to the $i$ th species and $H_{\max }=$ species diversity under conditions of maximum equitability. Multivariate procedures were applied during the analysis of macroinfauna assemblages (considering each family as a variable and abundance as an attribute) using the Primer v.5.2.0 software package (Plymouth Marine Laboratory). The samples were classified into macroinfaunal groups using a similarity matrix calculated with the Bray-Curtis coefficient for untransformed data. The similarity matrix was used both in the hierarchical cluster and in the non-metric multidimensional scaling (MDS). The quality of fit of the MDS is expressed as the stress. The families that contributed most to the similarity within groups and to the dissimilarity between groups were identified using the SIMPER (similarity percentages) procedure (Warwick et al. 1990, Clarke 1993). To assess the relationship between the environmental and the biological data, the BIOENV procedure (Clarke 1993, Clarke \& Ainsworth 1993) was applied. This procedure selects the environmental variables that may best explain the community pattern, maximising the correlation between their respective similarity matrices. A weighted Spearman correlation coefficient was applied.

\section{RESULTS}

\section{Densities of wild fishes}

The densities of the main wild fishes species $1000 \mathrm{~m}^{-3}$ observed in winter in the water column around the farm area were Dicentrarchus labrax, $12 \pm 6$ individuals; Diplodus annularis, $15 \pm 5$; Oblada melanura, $15 \pm 3$; Sarpa salpa, $5 \pm 2$; Mugilidae, $110 \pm 13$; those in summer were Oblada melanura, $52 \pm 20$ individuals; Sarpa salpa, $39 \pm 16$; Mugilidae, $86 \pm 8($ mean $\pm \mathrm{SE})$.

The densities of the main wild fishes species $100 \mathrm{~m}^{-2}$ in winter in the benthic area around the farm area were Diplodus vulgaris, $7 \pm 2$ individuals; Lithogbathus mormyrus, $7 \pm 2$; Mullus barbatus, $2 \pm 1$; Bothus podas, $2 \pm 1$; Mugilidae, $3 \pm 1$; those in summer were Diplodus vulgaris, $8 \pm 3$; Lithogbathus mormyrus, $7 \pm 2$; Mullus barbatus, $2 \pm 1$, Bothus podas, $2 \pm 1$; Mugilidae, $2 \pm 1$.

Table 1. Community indices (means $\pm \mathrm{SE}, \mathrm{n}=4$ ) for each type of treatment at end of the experimental period. ns: no significant difference

\begin{tabular}{|lcccc|}
\hline Index & Control & Open cage & Exclusion cage & Statistic \\
\hline Diversity & $0.73 \pm 0.34$ & $0.57 \pm 0.29$ & $0.22 \pm 0.15$ & $\mathrm{~ns}$ \\
Richness & $0.73 \pm 0.19$ & $0.79 \pm 0.35$ & $1.38 \pm 0.79$ & $\mathrm{~ns}$ \\
Evenness & $0.37 \pm 0.14$ & $0.29 \pm 0.11$ & $0.06 \pm 0.03$ & $\mathrm{~ns}$ \\
Dominance & $0.75 \pm 0.13$ & $0.83 \pm 0.09$ & $0.96 \pm 0.03$ & $\mathrm{~ns}$ \\
No. of species & $3.5 \pm 0.5$ & $4.25 \pm 1.37$ & $14.00 \pm 8.02$ & $\mathrm{~ns}$ \\
\hline
\end{tabular}

\section{Benthic cage experiments}

Particle-size analyses pointed to similar gravel:sand: silt/clay compositions for all cages: control $=0.98$ : 96.44:2.58; open cage $=0.76: 96.19: 3.05$; exclusion cage $=0.64: 94.10: 5.26$. There were no significant differences in sediment grain size between the 3 types of structures (Kruskal-Wallis, $p>0.05$ ). The fact that cage structure did not influence the sediment grain size suggests that the cages did not cause substantial hydrodynamic changes.

The effect of the different treatments on the organic content of the sediment varied (Fig. 2a). The organic matter content increased only slightly in the open cages, but more than doubled in the exclusion cages in the same area. The increase in organic matter differed significantly between treatments (Kruskal-Wallis, p < 0.05). There were significant differences between the exclusion cages and the control (Kruskal-Wallis, p < 0.05).

The C:N atomic ratio decreased in both the open cages and the exclusion cages (Fig. 2b). There were significant differences between treatments (KruskalWallis, $\mathrm{p}<0.05$ ). There were significant differences between the exclusion cages and the control (KruskalWallis, $\mathrm{p}<0.05$ ).

The quantities of TAN dissolved in the interstitial water showed a clear tendency to increase within the cages (Fig. 2c), and the increase of TAN in the sediment was significant (Kruskal-Wallis, $p<0.05$ ). There were significant differences (Kruskal-Wallis, p < 0.05) between both the control and the open cages and the control and the exclusion cages.

The AVS increment in the sediment (Fig. 2d) was significant (Kruskal-Wallis, $\mathrm{p}<0.05$ ). There were significant differences (Kruskal-Wallis, $\mathrm{p}<0.05$ ) between all treatments.

The abundance of the invertebrate community increased significantly in the exclusion cages (KruskalWallis, $p<0.05$ ), being approximately 16 times greater in the exclusion cages than in the open and control cages (Fig. 2e). The differences between open cages, exclusion cages and control were significant in all paired combinations of treatments (Kruskal-Wallis, $\mathrm{p}<0.05)$.

The abundance of Capitellidae (Fig. 2f) increased significantly in the exclusion cages (Kruskal-Wallis, p < 0.05). The differences between open cages, exclusion cages and the control were significant in all paired combinations of treatments (Kruskal-Wallis, $\mathrm{p}<0.05$ ).

The results of the Shannon-Wiener diversity, Margalef richness, Pielou evenness and Simpson dominance indices are 

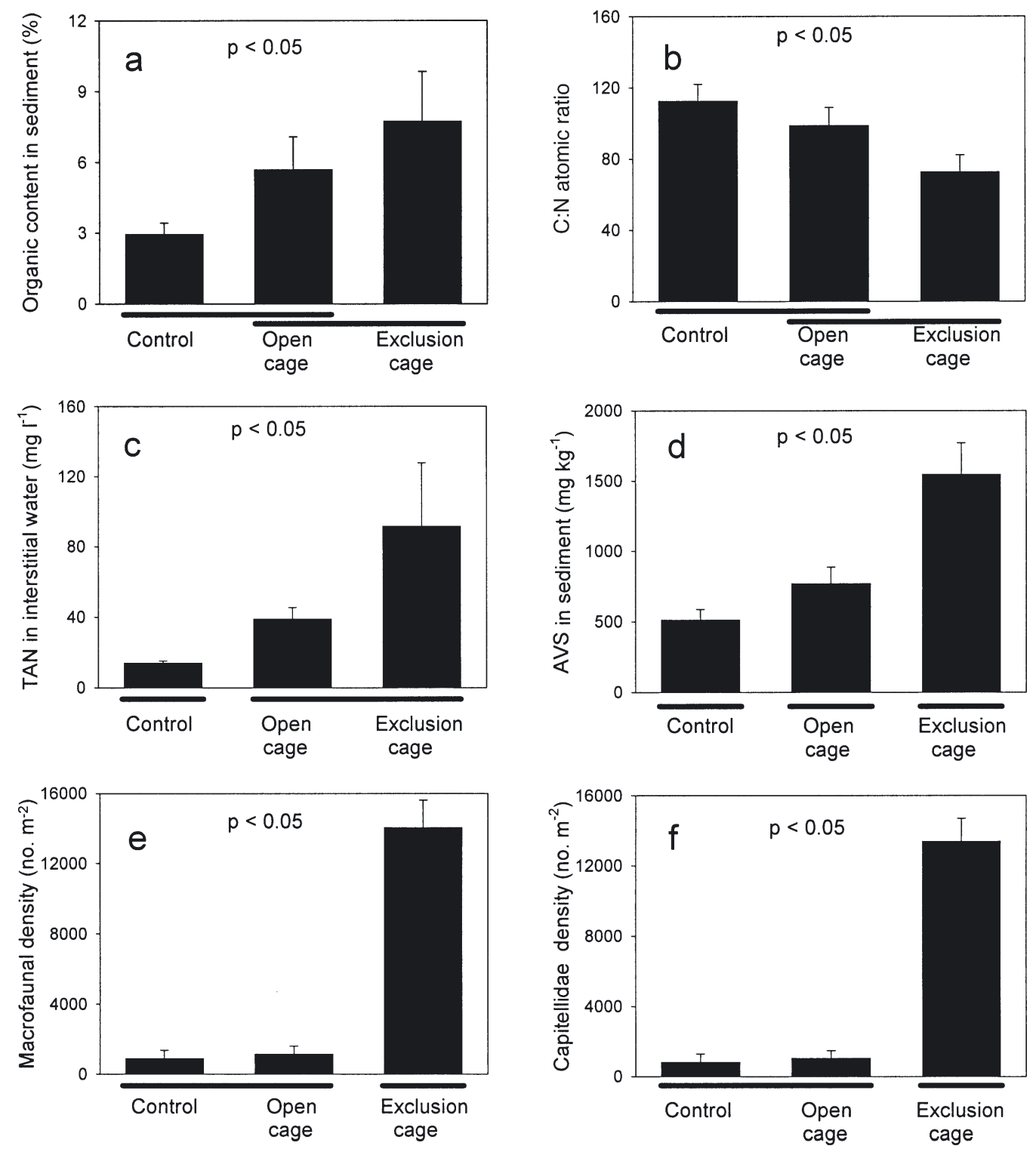

Fig. 2. Results of benthic experiments (means $+\mathrm{SE}, \mathrm{n}=4$ ). Horizontal bars beneath histogram bars connect treatments that are not significantly different ( $\mathrm{p}>0.05$; Kruskal-Wallis test). (a) Fraction of organic matter (loss on ignition); (b) C:N atomic ratio; (c) total ammonia nitrogen (TAN) dissolved in the interstitial water; (d) acid-volatile sulphide (AVS) concentration in dry sediment; (e) abundance of macrofauna in sediment; (f) abundance of Capitellidae in sediment

shown in Table 1. There were no significant differences (ANOVA, p > 0.05) between treatments for any of these indices.

The caging treatment had a clear effect on the structure of the benthic community, and the dissimilarity between the exclusion cage and the other treatments was high in all cases (control vs open cage $=48.45 \%$, exclusion cage vs open cage $=86.10 \%$, exclusion cage vs control $=89.03 \%$ ). A SIMPER analysis of the contributions of individual species to treatment dissimilarity for those families that contributed more than $1 \%$ revealed that in the case of the exclusion cages, only 2 families explained most of the dissimilarity from the other groups (exclusion cage vs open cage: Capitellidae $95.15 \%$, Nereidae $1.49 \%$; exclusion cage vs control: Capitellidae $95.41 \%$, Nereidae $1.38 \%$; while in the case of control versus open cages 8 families were involved Capitellidae: $78.60 \%$; Nereidae: $9.44 \%$; Veneroidea: $1.55 \%$; Ariciidae: $1.48 \%$; Arenicolidae: $1.45 \%$; Spionidae: $1.14 \%$; Brachyura: $1.14 \%$; Nebaliacea: $1.01 \%)$.

Non-parametric multidimensional scaling (MDS) classified the samples into 2 main groups. The first group was comprised of the samples in the exclusion 


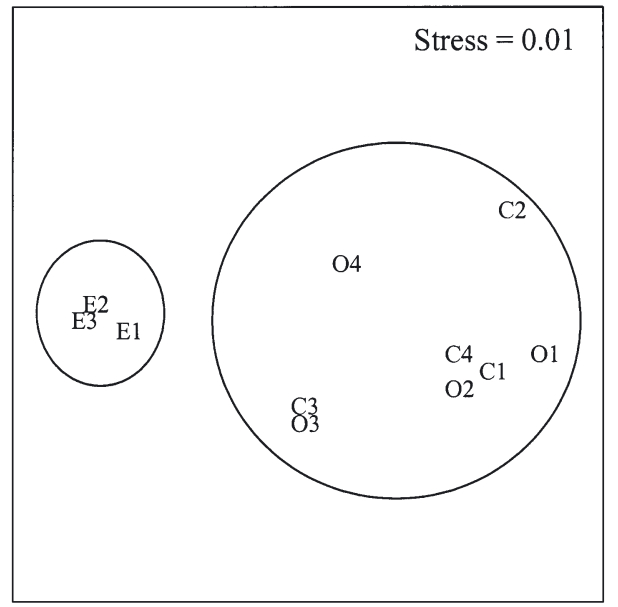

Fig. 3. Non-metric multi-dimensional scaling plot of control $(C)$, open cage $(\mathrm{O})$ and exclusion cage $(\mathrm{E})$ treatments; numbers are numbers of replicates

cages, while the second group reflected the spatial heterogeneity of the samples in the open cages and the control (Fig. 3).

BIOENV analyses revealed a strong correlation between the TAN plus $\mathrm{C}: \mathrm{N}$ atomic ratio and percentage of sand and lime (weighted Spearman coefficient, $\rho=0.518$ ). Two of the variables (TAN and percentage of sand) showed a high correlation (weighted Spearman coefficient, $\rho=0.433$ ).

\section{Water-column assays}

A comparison of organic waste (Fig. 4a) at the different depths revealed significant differences (1-way ANOVA, $p<0.01)$. The $\mathrm{C}: \mathrm{N}$ atomic ratio also varied as a function of depth (Fig. 4b), being significantly lower at the bottom of the rearing net-pens (1-way ANOVA, $\mathrm{p}<0.001$ ).

The amount of organic waste collected in the control traps was significantly lower (usually $>100$-fold) than in the sediment traps under the net-pens (1-way ANOVA, p < 0.05).

\section{DISCUSSION}

Poor feeding efficiency in net-pen aquaculture may provide a large food source for many native fishes. Artificial structures may provide protection against predators. Our wild-fishes counts agreed with those of Dempster et al. (2002) at the same farm in autumn 2001. In 9 different floating sea-cage fish farms in the south-western Mediterranean, Dempster et al. (2002) found a greater abundance, biomass and number of fish species than in control counts. We found similar wild fishes assemblages during our winter and summer experiments.

The sediment trap experiment showed that about $80 \%$ of the organic matter in particle form that actually sinks below the rearing net-pens can be consumed within the first $4 \mathrm{~m}$ and never reaches the bottom sediment. The amount of particulate organic matter that actually reaches the bottom beneath the net-pens has been estimated at $20 \%$ of the total. Phillips et al. (1985) found that food from net-pen aquaculture operations was being consumed by native fishes and gut analysis revealed that $98 \%$ of the food in the guts of native fishes was fish food. Johansson et al. (1998) incorporated inert indicator particles into the feed of a fish farm, which were later found in the gut contents of nearby wild fishes. We found that feeding by wild fishes decreases the nutritional quality of organic wastes before they reach the sediment. The $\mathrm{C}: \mathrm{N}$ ratio of waste outputs increased from 8.79 to 17.10 during settlement through the water column (Fig. 1). Holmer et al. (2002) found that the $C: N$ sediment ratios were generally lower inside (14 to 16 ) than outside (18 to 45) fish pens. In contrast, Sutherland et al. (2001), found only small differences between the C:N ratio in sedi-
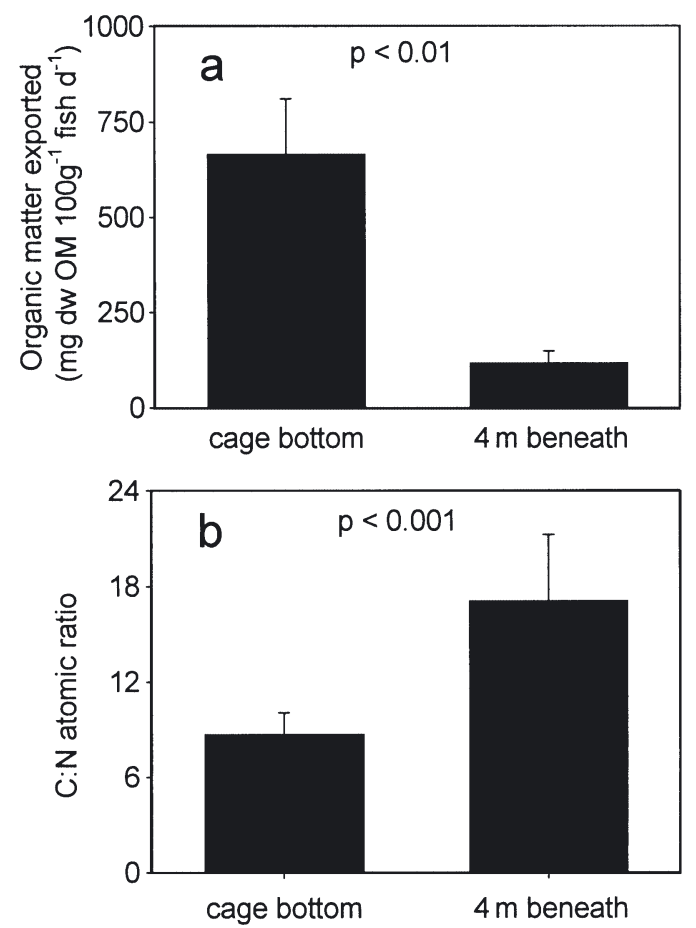

Fig. 4. Results obtained with sediment traps at 2 different depths in water column (bars give mean $+\mathrm{SE}, \mathrm{n}=12$ ). (a) Organic matter content (OM loss on ignition) of settled particles; (b) quality of wastes trapped, measured as $\mathrm{C}: \mathrm{N}$ atomic ratio 
ment traps and controls, with the traps exhibiting C:N weight ratios of 6 to 10, i.e. within the usual range observed for marine organic matter. Direct visual underwater observations confirmed that feed pellets are quickly consumed as soon as they leave the netpen. The consumption of food and faecal pellets by wild fishes should help in the dispersion and mineralization of organic matter through digestion and physical transport before excretion.

However, despite the foraging impact of wild fishes on pellets in the water column, organic wastes still reach the sediment. The rate of accumulation of excess organic material via sedimentation is a significant factor in benthic ecosystems, and can determine the species composition and secondary production of benthic communities. The sediment layer provides a habitat for a wide range of organisms while, at the same time, many important chemical processes occur in this layer. Microcosm experiments have demonstrated that benthic infauna can significantly increase the degradation rate of organic matter, although the exact mechanisms have not been completely described (Hansen \& Blackburn 1992, Kristensen et al. 1992). The presence of polychaetes (Capitella spp.) in the sediment increases the $\mathrm{O}_{2}$ and $\mathrm{CO}_{2}$ exchange between the siltsediment and the water column by between 70.9 and 131.4\% (Holmer et al. 1997). Dempster et al. (2002) studied aggregations of wild fishes around 9 floating net-pen farms along $300 \mathrm{~km}$ of the southwestern Mediterranean coast, and found that closer to the coast, and in shallow waters, species associated with benthic environments were prominent. Katz et al. (2002) concluded that while foraging for food and swimming near the sediment surface, mullets resuspend detritus, increase the oxygen supply to the benthos and oxygenate buried organic matter, thereby dramatically improving the status of organically enriched, reduced sediments within a relatively short period of time. Porter et al. (1996) also found that mullet activity significantly improved the sediment quality under a marine fish farm. Wild fishes activity on the seabed may therefore change sediment conditions by bioturbation. Wild fishes feed on organic wastes, feed and faecal pellets, as well as on other benthic opportunistic species. Our caging experiments on the sediment aimed to clarify the influence of wild fishes on sediments enriched by fish-farm waste.

One of the undesirable artefacts resulting from the use of experimental cages could be hydrodynamic changes, resulting in the accumulation of particles of a smaller size. In our experiments we found no significant changes in the granulometry in any of the treatments, indicating that the mesh size of the experimental cages did not affect current flow to any great extent. Comparison of the open cages and the controls did not show any significant changes between the physical and chemical parameters, except for TAN. The main effect of excluding the wild fishes was an accumulation of organic matter (Fig. 2a), which had a lower C:N ratio (Fig. 2b) than at control sites, leading to the production of reduced toxic compounds such as hydrogen sulphide $\left(\mathrm{SH}_{2}\right)$ (Fig. 2d) and ammonium $\left(\mathrm{NH}_{4}\right)$ (Fig. 2c). It has been observed that the amount of ammonium released from sediments under and near the perimeter of floating net-pens is higher than that released further away (Holmer \& Kristensen 1992, Hargrave et al. 1993). The increased concentration of TAN in the interstitial water of the sediments in the exclusion cages rose to reach levels which Cesar et al. (2000) considered as toxic to Mediterranean amphipods. Toxicity associated with $\mathrm{NH}_{4}$ and $\mathrm{SH}_{2}$ could determine which fauna able to colonise these sediments. The macrobenthic communities close to the rearing net-pens of marine farms are dominated by opportunistic organisms such as Capitella spp. (Loch et al. 1996, Karakassis et al. 2000). In the present case, the Polychaeta families Capitellidae and Nereidae, indicators of organic contamination, prevailed in the sediments near the floating net-pens, and were almost the only species able to withstand the conditions when wild fishes were excluded.

The environmental impact of fish farms involves changes in the diversity, abundance and biomass of macrobenthic species. The sediment experiments described in the present paper were carried out in a long impacted area, so the exclusion experiment involved high stress, but not a shift from a nonimpacted to a polluted state. The main effect of the prevention of wild fishes predation on benthic fauna was a much higher density of polychaetes in the exclusion cages. The benthic community indices did not provide a clear picture, probably because the area was already highly impacted, but multivariate analyses showed a clearer result. The 2-dimensional MDS ordination separated the sampling stations into 2 groups: a highly homogeneous group, corresponding to the exclusion cages, and a second group comprised of controls and open-cage treatments (Fig. 3). This ordination again emphasises the low effect directly attributable to the cage structure, since communities in controls and open-cage treatments were grouped together. Wild-fish predation could explain the differences in the community structure. BIOENV analyses suggested that wild-fish bioturbation decreased the TAN and C:N atomic ratio of the sediment. Thus higher toxicity due to excess organic matter and less fish predation could favour pollution-tolerant species.

In conclusion, the nutrient quality of the organic matter expelled by fish farms may be significantly changed by wild-fish consumption (Fig. 1). Particles 
collected in the traps indicated direct consumption of the pellets by wild fishes in the water column, decreasing their nutritional value. Similar trends were found in the sediment, attributable to wild fishes exhausting the high nutrient content of settled particles. Changes in the nutrient quality of fish-farm sediments could be due to direct consumption of wastes by benthic organisms (wild fishes and invertebrates). Biotic assimilation of nutrients helps in the exportation and dispersion of organic wastes resulting from aquaculture activity. The benthic effects of fish-farming have been investigated worldwide, although the results of studies from different parts of the globe are not necessarily directly comparable. Many studies have suggested that environmental impact is highly correlated with location (Karakassis et al. 1999, Kraufvelin et al. 2001). Henderson et al. (2001) identified the key areas of modelling uncertainty as: settling velocities/faecal quality, feed type, dispersion coefficients, resuspension parameters and characteristics, whole water-body/multi-farm impacts, holding capacity, nutrient fluxes and ecosystem effects. In this study we found that wild fishes do indeed enhance nutrient cycling in the water column as well as on the seabed, and furthermore they regulate benthic community structure. Our results indicate that the trophic role of wild fishes should be considered in environmental impact studies on fish farms.

Acknowledgements. This work was carried out within the framework of a CICYT-FEDER research program (project 1FD97-1128) in collaboration with CULMAREX S.A.

\section{LITERATURE CITED}

Allen HE, Gongmin F, Deng B (1993) Analysis of acid volatile sulfide (AVS) and simultaneously extracted metals (SEM) for estimation of potential toxicity in aquatic sediments. Environ Toxicol Chem 12:1441-1453

APHA (American Public Health Association) (1995) Standard methods for the examination of water and wastewater. American Public Health Association, Washington, DC.

Buchanan JB (1984) Sediment analysis. In: Holme NA, Mcintyre AD (eds) Methods for the study of marine benthos. Blackwell, Cambridge, p 41-65

Cesar A, Marin L, Vita R, Gomez M, Jiménez B, Marin A (2000) Test de toxicidad con sedimento marino en la costa mediterránea empleando anfípodos: Gammarus aequicauda y Microdeotopus gryllotalpa. In: Gaeta EL, Botta CMR, Rocha O, Camino MB, Lopes de Oliveira A (eds) Ecotoxicología: perspectivas para o Século XXI. Rima Editora, Sao Carlos, p 17-27

Cho CY, Bureau DP (1997) Reduction of waste output from salmonid aquaculture through feeds and feeding. Prog Fish Cult 59:155-160

Clarke KR (1993) Non-parametric multivariate analyses of changes in community structure. Aust J Ecol 18:117-143

Clarke KR, Ainsworth, M (1993) A method of linking multivariate community structure to environmental variables. Mar Ecol Prog Ser 92:205-219
Dempster T, Sanchez-Jerez P, Bayle-Sempere JT, GiménezCasalduero F, Valle F (2002) Attraction of wild fishes to sea-cage fish farms in the south-western Mediterranean Sea: spatial and short-term temporal variability. Mar Ecol Prog Ser 242:237-252

Gowen RJ, Weston DP, Ervick A (1991) Aquaculture and the benthic environment: a review. In: Cowey $\mathrm{CB}$, Cho $\mathrm{CY}$ (eds) Proceedings of the First International Symposium on Nutritional Strategies in Management. Nutritional Strategies and Aquaculture Waste. University of Guelph, Guelph, ON, pp 186-205

Hansen LS, Blackburn TH (1992) Mineralization budgets in sediment microcosms: effect of the infauna and anoxic conditions. FEMS Microbiol Ecol 102:33-43

Hargrave BT, Duplisea DE, Pfeiffer E, Wildish DJ (1993) Seasonal changes in benthic fluxes of dissolved oxigen and ammonium associated with marine cultured Atlantic salmon. Mar Ecol Prog Ser 96:249-257

Heilskov AC, Holmer M (2001) Effects of benthic fauna on organic matter mineralization in fish-farm sediments: importance of size and abundance. ICES J Mar Sci 58: 427-434

Henderson A, Forrest DAM, Black KD, Park MT (1997) The lipid composition of sealoch sediments underlying salmon cages. Aquaculture 158(1-2):69-83

Henderson A, Gamito S, Karakassis I, Pederson P, Smaal A (2001) Use of hydrodynamic and benthic models for managing environmental impacts of marine aquaculture. J Appl Ichthyol 17:163-172

Holmer M, Kristensen E (1992) Impact of fish cage farming on metabolism and sulfate reduction on the underlying sediments. Mar Ecol Prog Ser 80:191-201

Holmer M, Forbes VE, Forbes TL (1997) Impact of the polychaete Capitella sp. I on microbial activity in an organicrich marine sediment contaminated with the plycicil aromatic hydrocarbon fluroranthene. Mar Biol 128:679-688

Holmer M, Marbá N, Terrados J, Duarte CM, Fortes MD (2002) Impacts of milkfish (Chanos chanos) aquaculture on carbon and nutrient fluxes in the Bolinao area, Philippines. Mar Pollut Bull 44:685-696

Johansson T, Hakanson L, Borum K, Persson J (1998) Direct flow of phosphorus and suspended matter from a fish farm to wild fishes in Lake Southern Bullaren, Sweden. Aquacult Engin 17:111-137

Karakassis I, Hatziyanni E, Tsapakis M, Plaiti W (1999) Benthic recovery following cessation of fish farming: a series of successes and catastrophes. Mar Ecol Prog Ser 184: 205-218

Karakassis I, Tsapakis M, Hatziyanni E, Papadopoulou KN, Plaiti W (2000) Impact of cage farming of fish on the seabed in three Mediterranean coastal areas. ICES J Mar Sci 57:1462-1471

Katz T, Herut B, Genin A, Angel DL (2002) Gray mullets ameliorate organically enriched sediments below a fish farm in the oligotrophic Gulf of Aqaba (Red Sea). Mar Ecol Prog Ser 234:205-214

Kaushik SJ (1998) Nutritional bioenergetics and estimation of waste production in non salmonids. Aquat Living Resour 11:211-217

Kraufvelin P, Sinisalo B, Leppäkoski E, Mattila J, Bonsdorff E (2001) Changes in zoobenthic community structure after pollution abatement from fish farms in the Archipelago Sea (N. Baltic Sea). Mar Environ Res 51:229-245

Kristensen E, Andersen FO, Blackburn TH (1992) Effects of benthic macrofauna and temperature on degradation of macroalgal detritus: the fate of organic carbon. Limnol Oceanogr 37(7):1404-1419 
Lemarié G, Martin JLM, Dutto G, Garidou C (1998) Nitrogenous and phosphorus waste production in a flow-through land-based farm of European seabass (Dicentrachus labrax). Aquat Living Resour 11:247-254

Levings CD (1994) Some ecological concerns for net-pen culture of salmon on the coasts of the northeast Pacific and Atlantic Oceans, with special reference to British Columbia. J Appl Aquacult 4:65-141

Loch DD, West JL, Perlmutter DG (1996) The effect of trout farm effluent on the taxa richness of benthic macroinvertebrates. Aquaculture 147(1-2):37-55

Lupatsch I, Kissil GW (1998) Predicting aquaculture waste from gilthead seabream (Sparus aurata) culture using a nutritional approach. Aquat Living Resour 11:265-268

Mazzola A, Mirto S, Danovarro R (1999) Initial fish-farm impact on meiofaunal assemblages in coastal sediments of the western Mediterranean. Mar Pollut Bull 38:1126-1133

McGhie TK, Crawford CM, Mitchell IM, O'Brien DO (2000) The degradation of fish-cage waste in sediments during fallowing. Aquaculture 187:351-366

Mirto S, La Rosa T, Gambi C, Danovarro R, Mazzola A (2002) Nematode community response to fish-farm impact in the western Mediterranean. Environ Pollut 116:203-214

Persson G (1990) Eutrophication resulting from salmonid fish culture in fresh and salt waters: Scandinavian experi-

Editorial responsibility: Otto Kinne (Editor), Oldendorf/Luhe, Germany ences. In: Cowey CB, Cho CY (eds) Proceedings of the First International Symposium on Nutritional Strategies in Management. Nutritional Strategies and Aquaculture Waste. University of Guelph, Guelph, ON, 163-185

Phillips MJ, Beveridge MCM, Ross LG (1985) The environmental impact of salmonid cage culture on inland fisheries: present status and future trends. J Fish Biol 27: $123-137$

Pillay TVR (1992) Aquaculture and the environment. Fishing New Books, Oxford

Porter CB, Krost P, Gordin H, Angel DL (1996) Preliminary assessment of grey mullet (Mugil cephalus) as a forager of organically enriched sediments below marine fish farms. Israeli J Aquacult 48:47-55

Read P, Fernandes T (2003) Management of environmental impacts of marine aquaculture in Europe. Aquaculture 226(1-4):139-163

Sutherland TF, Martin AJ, Levings CD (2001) Characterization of suspended particulate matter surrounding a salmonid net-pen in the Broughton Archipielago, British Columbia. ICES J Mar Sci 58:404-410

Warwick RM, Platt HM, Clarke KR, Agard J, Gobin J (1990) Analysis of macrobenthic and meiobenthic community structure in relation to pollution and disturbance in Hamilton Harbour, Bermuda. J Exp Mar Biol Ecol 138:119-142

Submitted: December 18, 2003; Accepted: April 6, 2004 Proofs received from author(s): July 30, 2004 